\title{
Commentary: Experience Sampling Methodology reveals similarities in the experience of passage of time in young and elderly adults
}

\author{
Adolfo Di Crosta * and Pasquale La Malva \\ Department of Psychology, University of Chieti-Pescara, Chieti, Italy
}

Keywords: aging, Experience Sampling Methodology, passage of time, time

\section{A commentary on}

Experience Sampling Methodology reveals similarities in the experience of passage of time in young and elderly adults

by Droit-Volet, S., and Wearden, J. H. (2015). Acta Psychol. (Amst.). 156, 77-82. doi: 10.1016/j.actpsy.2015.01.006

\section{OPEN ACCESS}

Edited by:

Rocco Palumbo,

Harvard Medical School,

United States

Reviewed by:

Chao Hu,

University of Toronto, Canada

*Correspondence:

Adolfo Di Crosta

adolfodicrosta@gmail.com

Specialty section:

This article was submitted to

Emotion Science,

a section of the journal

Frontiers in Psychology

Received: 25 July 2017

Accepted: 31 July 2017

Published: 10 August 2017

Citation:

Di Crosta A and La Malva P (2017) Commentary: Experience Sampling

Methodology reveals similarities in the

experience of passage of time in

young and elderly adults.

Front. Psychol. 8:1384.

doi: 10.3389/fpsyg.2017.01384
Few studies have investigated differences in judgments of passage of time between younger and older adults, and the results seem contradictory. Generally, people report that time goes faster as they get older (Lemlich, 1975) which is due to the pressure of perceived time (Janssen et al., 2013). However, Wittmann and Lehnhoff (2005) and Friedman and Janssen (2010) found no clear differences of how passage of time perception changes with aging.

The article by Droit-Volet and Wearden (2015) investigated this issue by using the Experience Sampling Methodology (ESM) technique and combining, for the first time, the assessment of the direct experience of the flow of time in everyday life in both younger and older adults. The study involved 15 younger adults and 14 older adults. Both groups conducted the experiment through the "Experience Sampling Methodology" (ESM) method, which involves submitting a questionnaire to participants at different times of the day using a smartphone provided by the experimenters, and asking them questions regarding the passage of time at different periods of the day. Although this method has been used in other studies regarding the evaluation of perception of time (Conti, 2001; Larson and von Eye, 2006), and it is frequently used in health psychology (e.g., Schwartz and Stone, 1998; Myin-Germeys et al., 2009), the use of it in cognitive psychology is unusual. Participants were also asked questions about the passage of time over longer periods of time (this week, this month, or this year), if they felt that time passed more quickly now than when they were younger or if they felt that time passes more quickly as people get older. The data obtained were analyzed in relation to additional variables, including: the affective state of the participants (positive vs. negative), the level of arousal, the relaxation, the difficulty of the activity, and the degree of attention invested in the activities. Although the passage of time in every-day life was significantly related to affective states and the degree of attention invested in their activities, the results showed no significant difference between the two groups regarding the answers to questions about the passage of time. Interestingly, both groups felt that time passes more quickly as they get older and that time passes faster in the present than when they were younger. Further investigation and different modalities of data collection will be needed in the future to determine whether or not more complex factors, such as the "reference effect," played a crucial role. In fact, the lack of differences between older and younger adults may have been influenced by the tendency of individuals to make judgments in relation to a salient comparison group rather than in absolute terms when responding to the self-report and 
peer-report questionnaires (e.g., Youyou et al., 2017). Both, younger and older adults may have probably compared, consciously or unconsciously, the passage of the last day/week/month/year based on their own criteria (i.e., their own recent experience of passage of time which varied between the two groups).

Compared to previous ones, this study emphasizes the innovative use of the ESM method. This method, unlike the paper and pencil questionnaires, offers the possibility of obtaining ecologically large data sets infiltrating in the participants' everyday life to determine directly how they perceive the passage of time (Mehl and Conner, 2012). In the article by Droit-Volet and Wearden there is no measure of the direct experience that participants have on the passage of time on specific daily life activities, but rather the general impression of how time seems to flow in everyday life. In future investigations, this interesting data regarding the impression could be accompanied by an objective and real measurement of the time spent in a certain activity carried out by the participants, to evaluate not only how time has passed (e.g., slow vs. fast) but also how much time has actually passed (e.g., in s, min, h). In particular, the activity carried out by the participant at the time of evaluation could play a very significant role not only in terms of the difficulty of the activity itself, or in the degree of attention invested in it, but also in terms of its affective value (Carstensen et al., 1999; Innamorati et al., 2013; Di Domenico et al., 2015, 2016; Zebrowitz et al., 2015). Based on the extensive literature on emotions and aging (for a review see Fairfield et al., 2015b; Mammarella et al., 2016a), affective contents may affect the performance of participants in different domains including memory, language, and perception (Fairfield et al., 2015a; Altamura et al., 2016; Mammarella et al., 2016b, 2017; Palumbo et al., 2017a,b). In this regard, the study of Droit-Volet et al. consider the overall emotional state of the participant in general (but this may not be determined by the type of activity carried out at that time, but by several other factors). This is related to the fact that, as indicated by the authors, it was not possible to systematically check all the activities carried

\section{REFERENCES}

Altamura, M., Padalino, F. A., Stella, E., Balzotti, A., Bellomo, A., Palumbo, R., et al. (2016). Facial emotion recognition in bipolar disorder and healthy aging. J. Nerv. Ment. Dis. 204, 188-193. doi: 10.1097/NMD.0000000000000453

Carstensen, L. L. (2006). The influence of a sense of time on human development. Science 312, 1913-1915. doi: 10.1126/science.1127488

Carstensen, L. L., Isaacowitz, D. M., and Charles, S. T. (1999). Taking time seriously: a theory of socioemotional selectivity. Am. Psychol. 54:165. doi: 10.1037/0003-066X.54.3.165

Chen, Y., Huang, X., Luo, Y., Peng, C., and Liu, C. (2010). Differences in the neural basis of automatic auditory and visual time perception: ERP evidence from an across-modal delayed response oddball task. Brain Res. 1325, 100-111. doi: $10.1016 /$ j.brainres.2010.02.040

Conti, R. (2001). Time flies: investigating the connection between intrinsic motivation and the passage of time. J. Pers. 69, 1-26. doi: 10.1111/1467-6494.00134

Di Domenico, A., Palumbo, R., Fairfield, B., and Mammarella, N. (2016). Fighting apathy in Alzheimer's dementia: a brief emotional-based intervention. Psychiatry Res. 242, 331-335. doi: 10.1016/j.psychres.2016.06.009 out by the participants on a daily basis, because they were too varied, but perhaps it would have been advisable to control the inherent value in these activities (Carstensen, 2006) asking the participants to rate the valence of their activities on a scale ranging from very negative to very positive. This would have allowed to divide the activities in positive, negative, and neutral to investigate not only the role of the valence in the perception of the passage of time but also the interaction between affective state and the valence of the activity on experience of passage of time. It is important to remark that in the study of DroitVolet et al. the authors only measured the affective state of the participants and, although the affective state may play an important role in the perception of passage of time, it is not possible to exclude its independence from the valence of the actions carried out. It is possible, in fact, that a subject with a certain affective state may report that time goes faster when performs positive actions compared to negative ones or vice versa.

In summary, the study of Droit-Volet et al. Emphasizes the innovative use of the ESM method in dealing with issues of cognitive psychology ecologically by taking into account a controversial issue regarding the possible change in the agerelated perception of time.

In future research, it may be interesting to investigate, through the use of ecological studies or with more simple and objective paradigm, the role played by emotional factors and therefore not only the general emotional state of the participants but also the value of the activities carried out. More objective studies may include the use of the Mismatch Negativity paradigm (e.g., Chen et al., 2010) to investigate differences between younger and older adults in the perception of time using, for example, neutral, positive, or negative auditory and visual stimuli.

\section{AUTHOR CONTRIBUTIONS}

All authors listed have made a substantial, direct and intellectual contribution to the work, and approved it for publication.

Di Domenico, A., Palumbo, R., Mammarella, N., and Fairfield, B. (2015). Aging and emotional expressions: is there a positivity bias during dynamic emotion recognition? Front. Psychol. 6:1130. doi: 10.3389/fpsyg.2015.01130

Droit-Volet, S., and Wearden, J. H. (2015). Experience Sampling Methodology reveals similarities in the experience of passage of time in young and elderly adults. Acta Psychol. (Amst). 156, 77-82. doi: 10.1016/j.actpsy.2015.01.006

Fairfield, B., Mammarella, N., Di Domenico, A., and Palumbo, R. (2015a). Running with emotion: when affective content hampers working memory performance. Int. J. Psychol. 50, 161-164. doi: 10.1002/ijop.12101

Fairfield, B., Mammarella, N., Palumbo, R., and Di Domenico, A. (2015b). Emotional meta-memories: a review. Brain Sci. 5, 509-520. doi: 10.3390/brainsci5040509

Friedman,W. J., and Janssen, S. M. J. (2010). Aging and the speed of time. Acta Psychol. (Amst). 134, 130-141. doi: 10.1016/j.actpsy.2010.01.004

Innamorati, M., Tamburello, S., Contardi, A., Saggino, A., Imperatori, C., Tamburello, A., et al. (2013). Psychometric properties of the attitudes toward self-revised in Italian young adults. Depres. Res. Treat. 2013:209216. doi: 10.1155/2013/209216

Janssen, S. M., Naka, M., and Friedman, W. J. (2013). Why does life appear to speed up as people get older? Time Soc. 22, 274-290. doi: 10.1177/0961463X13478052 
Larson, E., and von Eye, A. (2006). Predicting the perceived flow of time from qualities of activity and depth of engagement. Ecol. Psychol. 18, 113-130. doi: 10.1207/s15326969eco1802_3

Lemlich, R. (1975). Subjective acceleration of time with aging. Percept. Mot. Skills 41, 235-238. doi: 10.2466/pms.1975.41.1.235

Mammarella, N., Di Domenico, A., Palumbo, R., and Fairfield, B. (2016a). When green is positive and red is negative: aging and the influence of color on emotional memories. Psychol. Aging 31, 914-926. doi: 10.1037/pag00 00122

Mammarella, N., Di Domenico, A., Palumbo, R., and Fairfield, B. (2016b). Noradrenergic modulation of emotional memory in aging. Ageing Res. Rev. 27, 61-66. doi: 10.1016/j.arr.2016.03.004

Mammarella, N., Di Domenico, A., Palumbo, R., and Fairfield, B. (2017). Self-generation and positivity effects following transcranial random noise stimulation in medial prefrontal cortex: a reality monitoring task in older adults. Cortex 91, 186-196. doi: 10.1016/j.cortex.2016.11.005

Mehl, M. R., and Conner, T. S. (2012). Handbook of Research Methods for Studying Daily Life. New York, NY: Guilford Press.

Myin-Germeys, I., Oorschot, M., Collip, D., Lataster, J., Delespaul, P., and Van Os, J. (2009). Experience sampling research in psychopathology: opening the black box of daily life. Psychol. Med. 39, 1533-1547. doi: 10.1017/S00332917080 04947

Palumbo, R., D'Ascenzo, S., Quercia, A., and Tommasi, L. (2017a). Adaptation to complex pictures: exposure to emotional valence induces assimilative aftereffects. Front. Psychol. 8:54. doi: 10.3389/fpsyg.2017. 00054
Palumbo, R., Fairfield, B., Mammarella, N., and Di Domenico, A. (2017b). Does make-up make you feel smarter? The "lipstick effect" extended to academic achievement. Cogent Psychol. 4:1327635. doi: 10.1080/23311908.2017.1327635

Schwartz, J. E., and Stone, A. A. (1998). Strategies for analyzing ecological momentary assessment data. Health Psychol. 17, 6-16. doi: 10.1037/02786133.17.1.6

Wittmann, M., and Lehnhoff, S. (2005). Age effects in the perception of time. Psychol. Rep. 97, 921-935. doi: 10.2466/pr0.97.3.921-935

Youyou, W., Stillwell, D., Schwartz, H. A., and Kosinski, M. (2017). Birds of a feather do flock together: behavior-based personality-assessment method reveals personality similarity among couples and friends. Psychol. Sci. 28, 276-284. doi: 10.1177/0956797616678187

Zebrowitz, L. A., Franklin, R. G. Jr., and Palumbo, R. (2015). Ailing voters advance attractive congressional candidates. Evol. Psychol. 13, 16-28. doi: $10.1177 / 147470491501300102$

Conflict of Interest Statement: The authors declare that the research was conducted in the absence of any commercial or financial relationships that could be construed as a potential conflict of interest.

Copyright (C) 2017 Di Crosta and La Malva. This is an open-access article distributed under the terms of the Creative Commons Attribution License (CC BY). The use, distribution or reproduction in other forums is permitted, provided the original author(s) or licensor are credited and that the original publication in this journal is cited, in accordance with accepted academic practice. No use, distribution or reproduction is permitted which does not comply with these terms. 